\section{Coagulation Failure after Vaginal Termination of Pregnancy}

\author{
S. V. SOOD
}

British Medical fournal, 1971, 4, 724

Coagulation failure complicating pregnancy was first described in 1771 by Hewson, while its association with abruptio placentae was reported by De Lee in 1901. Since the report by Dieckmann (1936) the defect in haemostasis has been ascribed to fibrinogen depletion. Bonnar et al. (1969) showed that fibrinogen depletion was only one aspect of a complex disturbance and that plasminogen and factors II, V, and VIII were also involved. They suggested that the high level of circulating degradation products was likely to be a major factor in defective haemostasis of abruptio placentae.

Fetal death in utero and missed abortion are other causes of failure in coagulation. Hardisty and Ingram (1965) found that this occurs in 1:3 to $1: 4$ cases where the dead fetus has been retained for more than four weeks. Courtney et al., (1971) showed an increased permeability of membranes of dead fetuses, which supports the hypothesis that this could be the cause in these cases.

Amniotic fluid embolism (Steiner and Lushbaugh, 1941) is a rare but very serious cause of failure of haemostasis. Liquor amnii may gain access to the maternal circulation as a result of a tear in the normal or abnormally friable dead membranes. The sudden severe shock may be due to an anaphylactoid reaction to antigenically foreign cells from the fetus. Courtney (1970) suggested that the hypotonia producing defective haemostasis in these cases is due to amniotic fluid infusion.

In the case described here coagulation failure occurred after vaginal termination of a 16-week pregnancy.

\section{Case Report}

A 24-year-old unmarried woman who had had one previous abortion was admitted to a private London nursing home for termination of pregnancy. Her general condition was good and the uterine size was compatible with a 16-week pregnancy. Vaginal termination of pregnancy was undertaken by dilatation and curettage under general anaesthesia, which was induced with thiopentone sodium and maintained by a mixture of nitrous oxide and oxygen.

At the end of the evacuation she began to have profuse vaginal haemorrhage. The "flying squad" was summoned. On their arrival the patient's general condition was found to be poor and she was in a state of shock, with a blood pressure of $90 / 50 \mathrm{~mm} \mathrm{Hg}$ and a pulse rate of $120 / \mathrm{min}$. There was a haematoma in the right antecubital fossa and blood was persistently oozing from the site of the venepuncture. The vulva, vagina, and cervix were bruised but there were no obvious lacerations. The uterus was anteverted, mobile, regular, and bulky and seemed to be contracting normally. The uterine cavity was empty.

The blood shed from the uterus and also a fresh venous specimen failed to clot. A provisional diagnosis of hypofibrinogenaemia was made and the patient was transfused with 1 unit $(540 \mathrm{ml})$ of quadruple-strength plasma and $\mathrm{O}$ rh-negative blood until emergency cross-matched blood was available, the haemorrhage being controlled meanwhile by bimanual compression. The laboratory report showed that the fibrinogen level in blood was less than $75 \mathrm{mg} / 100 \mathrm{ml}$. She

West Middlesex Hospital, Isleworth, Middlesex S. V. SOOD, M.R.C.o.G., F.R.C.S.ED., Senior Registrar in Obstetrics and was given $4 \mathrm{~g}$ of fibrinogen and 3 units $(1,620 \mathrm{ml})$ of rh-positive blood, after which she made a rapid recovery and her general clinical condition improved. The uterine bleeding almost stopped and a fresh venous specimen showed normal clotting, though a large bruise appeared in the subumbilical area on the anterior abdominal wall, which was thought to have been caused by the bimanual compression.

The patient was transferred to hospital, and as there was still a tendency for the uterus to bleed the cavity was packed with 6 in $(15 \mathrm{~cm})$ sterile gauze under general anaesthesia. She was transfused with a further 3 units $(1,620 \mathrm{ml})$ of whole blood. Prophylactic ampicillin therapy was started. Her general condition remained good and there was no further haemorrhage. The pack was removed after 24 hours. Full blood counts on the second and tenth postoperative days were normal and the platelets were $204,000 / \mathrm{mm}^{3}$ on the second day. There was no evidence of any haemorrhagic diathesis. She remained apyrexial and was dicharged on the tenth postoperative day.

\section{Comment}

The occurrence of blood coagulation failure is not a recognized complication of termination of pregnancy. The mechanism of coagulation failure due to hypofibrinogenaemia in this case remains obscure. Though preoperative studies on blood were not undertaken there was no reason to suspect any abnormality, as the patient had had a vaginal termination a year previously without mishap. There was no question of fetal death. Intrauterine sepsis was unlikely as there was nothing to suggest that a criminal attempt at abortion had been made. The fetus was formed and the placenta did not show hydatidiform change. A possible explanation could be the escape of liquor amnii into the maternal circulation, causing shock and hypofibrinogenaemia due to fibrinogen-fibrin conversion.

From the practical standpoint the diagnosis of coagulation failure is essentially a clinical one, and on this evidence alone prompt action is often necessary to save the patient from fatal haemorrhage. In such circumstances time is too short to allow laboratory tests to be carried out to determine the coagulation and fibrinolytic status of a patient's blood-in any case, facilities to undertake such tests are not always readily available. If coagulation is found to be defective, as shown by simple bedside tests, but there is no evidence of dangerous or excessive bleeding it is wise to avoid specific therapy unless surgical treatment has to be undertaken. When haemorrhage is excessive transfusion of fresh blood should be given because stored blood will cause further depletion of platelets and factors V and VII, which are notoriously labile in stored blood (Ingram, 1965).

I thank Mr. D. A. Davies for permission to report this case, and Professor J. S. Scott for helpful advice.

\section{References}

Bonnar, J., Davidson, J. F., Pidgeon, C. P., McNicol, C. P., and Douglas, A. S. (1969). British Medical fournal, 3, 137.

Courtney, L. D. (1970). British Medical fournal, 4, 303. Courtney, L. D., Boxal, R. R., and Child, P. (1971). British Medical fournal, 1, 492

De Lee, J. B. (1901). American fournal of Obstetrics and Diseases in Women, 44, 785

Dieckman, W. J. (1936). American fournal of Obstetrics and Gynecology, 31, 734 .

Hardisty, R. M., and Ingram, G. I. C. (1965). Bleeding Disorders: Investigation and Management. Oxford, Blackwell Scientific.
Int

Hewson, W. (1971). An Experimental Inquiry into the Properties of the Blood, with Remarks on Some of its Morbid Appearances. Quoted in The Works of William Hewson, F.R.S., ed. G. Gulliver, p. 69. London, Sydenham Society, 1846.

Ingram, G. I. C. (1965). Transfusion (Philadelphia), 5, 1.

Steiner, P. E., and Lushbaugh, C. C. (1941). Fournal of the American Medical Association, 117, 1245, 1340. 